\title{
Reframing tacit human-nature relations: An inquiry into process philosophy and the philosophy of Michael Polanyi \\ Roope Oskari Kaaronen
}

\begin{abstract}
To combat the ecological crisis, fundamental change is required in how humans perceive nature. This paper proposes that the human-nature bifurcation, a deeply entrenched and potentially environmentally unsound metaphysical mental model, stems from embodied and tacitly held substance-biased belief systems. Process philosophy can aid us, among other things, in providing an alternative framework for reinterpreting this bifurcation by drawing an ontological bridge between humans and nature, thus providing a coherent philosophical basis for sustainable dwelling and policy-making. Michael Polanyi’s epistemology can further help us understand these environmentally oriented tacit processes of knowing, and also provide a basis for political and educational implementations of process-philosophical insights, particularly via the nudging of mental models.
\end{abstract}

\section{Keywords}

Process metaphysics, tacit knowledge, sustainability, environmental policy, nudging.

\section{Introduction}

In recent years, there have been several calls for a better understanding of the interconnections between human, societal and natural systems. In particular, several writers have proposed that some sort of cognitive 'reframing' is required, if we are to come to appreciate the fundamental relations between humans and the ecosystems to which they belong (Honig et al., 2015: 677; Hukkinen, 2012; Richardson et al., 2015). Whilst this 'art of the cognitive war to save the planet' is undoubtedly a political task, involving both systemic and behavioural 
Forthcoming in Environmental Values @The White Horse Press http://www.whpress.co.uk

change, it can also be interpreted to represent a philosophical - even metaphysical endeavour of reframing the ontological and epistemological relationship between the human and its environment (Antal and Hukkinen, 2010; Hukkinen, 2012). Accordingly, revised comprehensions of the relationship between individual actors and socio-ecological systems (SES's) have been called for to transcend dichotomous frameworks such as human-nature, human-environment, realism-constructionism and individual-SES (Antal and Hukkinen, 2010; Hukkinen, 2012). I suggest in this article that environmental philosophers and policymakers might find two particularly interesting philosophical allies in (1) process philosophy and (2) Michael Polanyi for reinforcing their tasks in drawing the bridges between the aforementioned dichotomies, thus strengthening the philosophical ties between society and environment.

The philosophical proposition I shall develop is a twofold argument built on the insights of process philosophy and Michael Polanyi's epistemology. Firstly, in Section 2, I wish to show that the dichotomies mentioned above, among others, arise from a predominantly substancebiased metaphysical framework, and that the best alternative to reframe these 'bifurcations of nature' is through a philosophy which emphasizes the ontological primacy of process over substance (Whitehead, 1978). I shall suggest, providing illustrative examples such as the coastline paradox, that a process-biased worldview might have the potential for inducing a sustainable 'Gestalt switch' (Kuhn, 2012) in how both the public and experts relate to and think about nature and the environment, as well as facilitate the development of the necessary policy tools to accomplish this.

Following the insights of process philosophy, in Section 3 I shall introduce some central ideas of polymath Michael Polanyi. What shall be proposed is that mental and bodily modes of knowing are fundamentally interconnected, and thus reframing some of our most fundamental, often tacit or implicit, substance-biased philosophical presumptions with 
Forthcoming in Environmental Values @The White Horse Press http://www.whpress.co.uk

process-philosophical alternatives might open doors for novel modes of sustainable behaviour and a revived appreciation of nature. Finally, in Section 4 the insights of process philosophy and Michael Polanyi shall be discussed in relation to their potential for setting a philosophical framework for environmental policy development. I particularly suggest that the nudging of our unsustainable mental models might result in an effective political and educational instrument.

However, there remains an important secondary motive for writing this article. The theoretical frameworks of both process philosophy and Michael Polanyi are often side-lined in mainstream philosophy and policy despite their obvious relevance to acute socioenvironmental concerns. Hence to reconsider process philosophy and Michael Polanyi's work - two strains of thought which have received generous praise from prominent thinkers Bruno Latour (foreword in Stengers, 2011) and Amartya Sen (foreword in Polanyi, 2009), respectively - under the aegis of environmental policy and philosophy holds, I argue, great potential for novel development towards a sustainable future.

\section{Perspectives on Process Philosophy}

\subsection{Process and Processists}

Process philosophy, generally considered an endeavour in speculative metaphysics, represents a long strain of thought which can be dated (in Western Europe) at least to pre-Socratic philosopher Heraclitus and his famous teaching that 'everything changes' ${ }^{1}$. Since Heraclitus, processists $^{2}$ alike have had the commonality of stressing the ontological (or at the very least, epistemological) primacy of process (i.e. change, movement, dynamism, flux, temporality,

\footnotetext{
${ }^{1}$ Often referred to as panta rhei ('everything flows').

2 A neologism developed by Nicholas Rescher (1996; 2000) along with related concepts 'substantialist', 'processual', 'processism' etc. in order to cope with the insufficient lexical resources in English for dealing with process-related issues.
} 
activity or other 'items better indicated by verbs than by nouns', see Table 1) over substance (i.e. static 'things') (Rescher, 2000: 4).

Due to its broad underpinnings, it comes perhaps as no surprise that process philosophy has historically found a large variety of interdisciplinary - or 'hybrid' (Hård and Jamison, 2005) applications, with notable advocates ranging from American pragmatists John Dewey, C.S. Peirce, G.H. Mead and William James, chemist-philosophers Ilya Prigogine and Isabelle Stengers to, most famously, mathematician-turned-philosopher Alfred North Whitehead (see Rescher, 1996). More recently, prominent process philosophy scholars include Nicholas Rescher (whose interpretation of process philosophy ${ }^{3}$ this text is most heavily based on) and Arran Gare, whilst process philosophy is also known to have influenced Bruno Latour. Interdisciplinary biologists such as Francisco Varela, Humberto Maturana and Stuart Kauffman might also be read to support process-philosophical endeavours in their theories of autopoietic or emergent systems. I also suggest in this article that Michael Polanyi (1969: 132) - a polymath whose intellectual career spanned physical chemistry, economics, social sciences and philosophy - might be considered amongst the processists, particularly due to his advocacy of the view that 'knowledge is an activity which would be better described as a process of knowing' and that science is a dynamic inquiry 'ever on the move'. However, before getting into further detail, a disclaimer should be placed that process philosophy cannot not be considered a unified doctrine or ideology, and it naturally follows that not every claim I make of process philosophy will apply to all those labelled 'process philosophers'.

\footnotetext{
${ }^{3}$ Which I regard the most coherent and accessible compilations of the general theses of process philosophy.
} 
Forthcoming in Environmental Values @The White Horse Press http://www.whpress.co.uk

\subsection{Process and Substance}

Western $^{4}$ (European) philosophy, broadly speaking, has predominantly been biased towards substance as the basic ontological unit of reality (Rescher, 1996: 29, 51; 2000: 3-4). Rescher notes that, as is often the case with philosophy, process philosophy is perhaps best understood against what it opposes: the ontological supremacy of substance over process. By reversing the ontological order of priority (that is, by prioritising process over substance) process philosophy can be interpreted to provide a philosophical framework for reinterpreting the paradigmatic bifurcations - most prominently the human-nature dichotomy - which have left a significant mark on human dwelling and its environmentally pathological manifestations. Instead of viewing substances (or things) as discrete entities, process philosophy reconceptualises substances as manifolds of process: substances are reduced from their status as ontologically separate entities to relatively static modes of dynamic process, always subject to pragmatic limitation in definition. As Rescher (1996: 28) articulates, 'substantial things emerge in and from the world's course of changes' and thus 'processes have priority over things'. For process philosophy, there is no fundamental ontological distinction between subject and object nor subject and predicate; an actor is not ontologically isolated from its environment nor is it ontologically separate from its dispositions (i.e. what it does). Rather, the world is best described a 'unified macroprocess', consisting of 'a myriad of duly coordinated subordinate microprocesses' (Rescher, 1996: 84).

One primary argument against substance-biased philosophy is its neglect (or downplay) of action. Indeed, if a substance does nothing, it lacks property and is thus meaningless - we can only know about 'things' as they relate to and interact with other 'things' (including the

\footnotetext{
${ }^{4}$ I duly acknowledge the problematic nature of the term 'Western' here, for two reasons. Firstly, 'Eastern' and 'Western' philosophies are often exaggeratedly contrasted and falsely stereotyped as 'holistic' and 'dualistic', respectively. Second, to reduce the question of cognitive bifurcation to merely being a 'Western' issue would not make for a coherent account of our biological and evolutionary tendency for dualism and bifurcation. See Slingerland, 2008 for related discussion.
} 
knower) (Rescher, 1996: 47). An entirely static world would have no qualities (Dewey, 1958: 90). Hence substance simply cannot do without process - yet the same does not apply when the parts are reversed (Rescher, 1996: 57, 62-3). Processes, such as climate change, can exist and be very real without having a static identifiable substantial form or spatiotemporal borders. It thus follows naturally for processists to ask: why insist on the separateness of static entities if they only appear as real when interacting? Is the world not more coherently portrayed as the interaction and interrelation of things, and if so, is process not ontologically precedent to the substance interactive processes temporarily manifest as? Accordingly, processists emphasize the pragmatic maxim that 'things' are better described as what they 'do' rather than what they 'are' (Rescher, 1996: 47; Whitehead, 1967: 157).

Process philosophy is thus best described as a one-tier ontology, where the bifurcations of thing-activity (and similarly, the primary/secondary quality distinction) and subject-object are replaced with a 'monism of activities of different and differently organized sorts' (Rescher, 1996: 49). The subject and object, generally separated in a substance metaphysics, are united as not different 'kinds' of substance but rather as pragmatically distinguishable 'degrees' of process. The difference between subject and object is hence not in kind but in degree. If process is taken to be the basic ontological unit (that is, all things are fundamentally processual), the matter of clearly distinguishing one thing from another is always suspect to fundamental limitations and is necessarily a pragmatic action.

An explicated definition of a thing, therefore, is analogous to taking a set of filmstrip-like photographs of a flying arrow: the photographs provide us interesting detail, but fail to exhibit the 'structure of spatiotemporal continuity' and thus the totality of the process (Rescher, 1996: 39). No fixed categories can completely capture the contingency of reality, although they are undeniably of extraordinary instrumental use. Yet still, for processists, 'once reality falls apart into disjointed discreteness, not all the king's horses and all the king's men can get it together 
Forthcoming in Environmental Values @The White Horse Press http://www.whpress.co.uk

again' - discreteness always induces loss of reality at the price of pragmatic value (Rescher, 1996: 40). Hence it follows that a process philosophy always adheres to a degree of incompleteness in explicated definition. I shall make use of Sen's (1995) concepts here to enlighten the question at hand: for process philosophy, explicated knowledge of reality always remains 'fundamentally incomplete' (reality is always in process and static descriptions cannot fully capture this dynamic) yet there remains all reason to be 'pragmatically incomplete' (i.e. make tangible sense of the process) by means of pragmatic limitation.

Here, it could be argued, is also the key for bridging the bifurcation of constructionismrealism through a framework of process philosophy: process philosophy is simultaneously realistic about process and idealistic about substance (yet the ontological priority is on the former). Process is basic 'and things derivative, since it takes a mental process (of separation) to extract "things" from the [Jamesian] blooming buzzing confusion of the world's physical processes' (Rescher, 2000: 7). Thus substance is always a category imposed on process, yet process remains real even without substance. The caveat is, though, that the act of categorisation or separation is not arbitrary since the structures of processes afford certain types of categories. As Rescher (1996: 71) articulates, 'abstraction [social construction] does not create structure but presupposes it [realism]' (brackets added for emphasis; see also Heft, 2001). Constructionism and realism are thus reframed as long lost relatives. Thus Dewey's (1958: 47) idea that philosophical feuds tend to be 'family quarrels' seems appropriate: these conflicts 'go on within the limits of a too domestic circle' and are best settled 'by venturing out of doors'. The realist-constructionist and idealist-realist debates mostly occur within a substance-metaphysical framework - perhaps they too are best settled through the 'outdoor' prospect of process philosophy. 
But what about the individual-system relation? This is certainly an imperative question for the ecological sciences. Process philosophy approaches this issue by adhering to the notion that reality is processual 'all the way down': processual entities themselves consist of clusters of processes (Rescher, 1996: 54-55). Processes are parts of wider structures and themselves contain inner structures, constituting what is essentially a nested holon (Koestler, 1967; Ostrom, 2005) or 'Chinese box' of processes within processes. Central to this organismic analogy is also its inherent notion of hierarchical emergence: lower processes form structures from which higher novel forms of processes emerge. Nature, it follows, is an integrated whole of emergent ${ }^{5}$ processes - it is humans who 'for our own convenience, separate them into physical chemical, biological and psychological aspects' (Rescher, 1996: 55). Since a process is always Janus-faced (it looks both inwards and outwards), causality and feedback is interpreted as two-directional: socio-ecological systems emerge from the interaction of its constituents (e.g. the dynamic relations between actors and natural resources), but the SES also has influence on how its dispositional particulars act within the system. As is generally the case with process philosophy, the difference between human actors and the SES is not in 'kind' but rather in 'degree'. A system is thus not some 'magical' entity hovering above the individual, but both emerges from individuals and has effect on how individuals operate (Hukkinen, 2012; Slingerland, 2008).

This is a particularly important notion since all too often cognitive and socio-ecological systems are treated as ontologically separate entities. Whilst the focus of this article is on the former, I wish to reemphasise that in order to achieve sustainability we require change in both macro systems and cognitive (micro) systems, and most importantly we need to acknowledge the reciprocal relationship between the two. This entails designing policies, societies, economies and environments which 'afford' (i.e. enable; Heft, 2001) the realisations of

\footnotetext{
${ }^{5}$ Thinkers such as Gare (1996), Polanyi (1958) and Kauffman (1995) have highlighted the necessity for humans to locate themselves in this process of natural emergence.
} 
Forthcoming in Environmental Values @The White Horse Press http://www.whpress.co.uk

sustainable mental models. Since process philosophy, at its heart, acknowledges and emphasises these reciprocal interconnections between micro and macro level systems, it is a particularly fit ontology for comprehensive sustainability transitions.

The strength of process philosophy also lies in its intrinsic dynamism: it can be advocated in either its ontological (strong) form or its epistemic (weak) form. Whilst ontological forms of process philosophy are by no means toothless against even the harshest critique ${ }^{6}$, process philosophy represents at the very least a pragmatic epistemic instrument for reconceptualising the basic premises that lie under an unsustainable culture. Thus, at the very least, process philosophy represents a pragmatic 'thought instrument' for organizing both everyday and scientific knowledge (Rescher, 1996: 25, 34, 165; 2000: 3-4). It is also worth emphasizing that process philosophy does not stand against materialism, but rather reconceptualises physically stable things as static 'stability waves' in a dynamic 'sea of process' (Rescher, 1996: 53). Process philosophy, in other words, does not do away with substance, but imposes an alternative way of looking at things by reducing the ontologically fundamental status of substance to what is best described as "pragmatic" ${ }^{\text {"7 }}$ or instrumental. It is also worth noting that process philosophy does not necessitate change in explicit language: it does not imply we explicitly call 'this pen' by the convoluted phrase 'this instance of a pen process' (Rescher, 1996: 33). Indeed, Rescher (ibid.) goes on to wittingly note how 'Copernicans have not desisted from speaking of sunrises'. However, what process philosophy does imply is a tacit Gestalt shift in how we relate to the world - these themes shall be returned to in more detail in Section 3.

\footnotetext{
${ }^{6}$ See e.g. Rescher's (1996) responses to P.F. Strawson's critique.

${ }^{7}$ Yet, importantly, the pejorative phrase 'merely pragmatic' would be ill-placed here.
} 


\subsection{Reframing Environmental Bifurcations}

Applied to environmental concerns, at least five potentially unsound features of substancebiased mental models are discussed below which might be pro-environmentally altered through the 'conceptual blend' (Fauconnier and Turner, 2002) of 'substance' reframed as 'process' (see Table 2). Moreover, since it is also particularly important to consider how changes in policy, behaviour settings and education, for instance, can help bring about these changes, some empirical examples of how a processual mode of thought or behaviour can be brought about by the means of policy and education are also provided.

(1) First is the ontological separation of things from their surroundings. This is best portrayed in the prominent mental framework between humans and their environment: nature is substantialized and commodified unsustainably, viewed as an ontologically separate order on which human subjects impose their sovereign will and control. Technological and economic progress is portrayed as a victory against nature, whilst in all reality seemingly independent individual actors are merely strengthening the processual feedback-relations between them and their socio-ecological environment through excessive and unsustainable material consumption (Latour, 1991; Antal and Hukkinen, 2010).

It seems, therefore, that a sustainable society has to further emphasise the interrelations between humans and their natural environment. Indeed, perceptions which emphasise ecological interconnectedness - as advocated by process philosophy - are often associated with pro-environmental behaviour (see e.g. Davis et al., 2009). In fact, Davis et al. (2009: 179) even go so far as to suggest that positive 'promotion focus on dependence and interconnectedness with the environment may yield longer lasting or more pervasive transformation of motivation' than negative 'approaches that highlight prevention or threat' (e.g. risk communication). Even if we duly acknowledge the existence of a significant 'valueaction gap' (Kollmuss and Agyeman, 2002) between reported value-sets and actual 
behaviour, the importance of mental models in promoting sustained pro-environmental behaviour patterns should not be overlooked, and reinforcing these sustainable mental models is an important task for any society wishing to strive towards sustainability.

(2) Second is the ontological separation between products and processes. Products are displayed and branded as hard-edged substance whilst production processes are (often deliberately) hidden and untraceable. Carefully branded products are not portrayed as process (e.g. how they became, how they were manufactured and how they will manifest as waste) but rather as discrete modes of substance separate from their environment. The action of inanimate things is downplayed, and feedback is often left unnoticed.

Whilst acknowledging the processual interconnectedness between things, production processes and their ecological consequences might itself lead to altered behaviour in consumption patterns, policymakers can also seek to take steps towards what could be called 'process-biased environmental policy'. This can happen, for instance, by directly strengthening feedback between 'subjects' (human consumers) and 'objects' (products), which is greatly facilitated by technological advances. For example, continuous electronic feedback in particular has been noted to be an effective tool for inducing pro-environmental behaviour changes (e.g. energy conservation), potentially also resulting in heightened awareness of environmental impacts (Abrahamse et al., 2007). Developing similar processual policies which strengthen the interconnections between products and consumers can thus contribute to significant positive changes in sustainable behaviour patterns.

(3) Third is the subjugated ontological status of change. Within a substance metaphysics framework, as has been noted above, change is often perceived to be less real than stability. This is a direct concern for an era in which understanding change is of primary concern for the survival of civilization. Environmental concerns, often dealing with slow, ambiguous and 
fuzzy modes of change (e.g. anthropogenic climate and environmental change), are commonly subjugated to more hard-edged and tangible ideas (e.g. material consumption and natural resource extraction). Alarmingly, the case with climate change in particular is that once its consequences become tangible, the changes might be irreversible. Thus we need to further understand how climate and environmental change, albeit slow and less tangible than our typical substances, are both real and highly consequential. Therefore, by reifying the ontological status of change, perhaps a processual approach to education could provide a framework for the reinterpretation complex and slow events such as climate change.

This could happen, for example, by promoting the use of experiential education (first-hand vivid involvement with environmental processes, dealing directly with environmental change) next to the more traditional substance-biased learning methods (such as learning about 'things' from static entities such as textbooks). Indeed, Epstein (1994: 711 in Leiserowitz, 2006: 48) notes that 'experientially derived knowledge is often more compelling and more likely to influence behavior than is abstract knowledge'. Similarly, Leiserowitz (2006: 63) suggests that 'experiential processes', or personally derived vivid and affect-laden knowledge gained from direct first-hand involvement (referred to later in this text as 'tacit' knowledge), most likely have heavy impact on risk perceptions over global warming.

(4) Fourth is the academic and intellectual division between constructionists and realists, which has effectively separated the 'hard' and 'soft' sciences and resulted in what are commonly referred to as the 'science wars' (Gould, 2000). If humans do not construct nature, nature appears as remote, foreign and hostile; if humans do construct nature, nature appears as artificial (Latour, 1991: 30-31). The effort to overcome this dilemma is apparent in much, if not most, of the social sciences in particular. As has been noted, a processual framework does not allow such a sharp distinction between constructionism and realism, and effectively 
Forthcoming in Environmental Values @The White Horse Press http://www.whpress.co.uk

unifies the two when claiming that whilst processes are real in themselves, any strict categorical imposition on them is fundamentally incomplete and thus potentially value-laden.

Moreover, process philosophy emphasises the fundamental interconnection between natural sciences, humanities and social sciences - an increasingly topical issue due to the 'hybrid' and multifaceted nature of most global problems (e.g. climate change) (Latour, 1991). Therefore, by emphasising the interconnected and gradient borders between scientific fields recall Rescher's (1996: 55) emphasis on how 'physical chemical, biological and psychological aspects' emerge from the same nested reality - process philosophy can also contribute to the development of inter- and transdisciplinary perspectives on sustainability and thus help overcome the disciplinary discordances most radically symbolised by the science wars.

(5) Fifth and last is the disjunction between systems and individuals: 'micro' and 'macro' are reframed as not bifurcated ontological entities but rather as mutually and reciprocally constituent (Latour, 1991; Heft, 2001). Individuals and systems are merged seamlessly within one philosophical framework without downplaying the influence of the actor nor that of the system. In a processual framework, therefore, individuals cannot merely 'blame the system' (since they themselves are, as cognitive actors, a part of the emergence of a system), although a marked change in the SES's institutional basis of course does have great effects on the processes and events that occur within it. This process philosophical emphasis of the reciprocity between cognitive and macro (be they termed socio-economic, socio-political or socio-ecological) systems should particularly guide policymakers in designing policies which not only develop pro-environmental knowledge or values (i.e. mental models) but also environments and societies which create 'affordances' (or action possibilities; Heft, 2001) for the realisation of these mental models. 
Conclusively, the primal question for process philosophy is not how the human acts environmentally, but rather how the human-embedded-in-nature manifests itself within a reciprocal socio-ecological process ${ }^{8}$. The human, for process philosophy, is not a separate entity with fixed borders, but rather part and parcel a manifestation of the 'megaprocess' we call nature (Rescher, 1996; 2000). These simple tenets emphasizes the notion that no human action happens without environmental consequences, and that feedback is always expected. Yet even more at that, process philosophy raises a fundamental question of our ontological identity with the natural process that we both constitute and are constituted by. To locate the human in the process of nature should, of course, come naturally for anyone remotely quaint with evolutionary theory (indeed, many of the early processists and pragmatists drew great influence from Charles Darwin), yet the fundamental bifurcation of human-nature still seems to remain strong in our cultural mythos, pathologically reinforcing phenomena such as ecocide, climate change, mass extinction and even evolution denialism (see e.g. Dawkins, 1993).

\subsection{The Coastline Paradox: An Illustrative Example}

A paradigmatic example of the central arguments related to process philosophy can be made with reference to the coastline paradox. Whilst the paradox is by nature mathematical (and, indeed, inspired Benoit Mandelbrot to develop fractal geometry), my reference to it shall be at best allegorical. Essentially, the paradox states that a coastline cannot have a completely defined length since the result of the measurement is inherently dependent on the method used to measure it. In other words, when measuring the coastline of, for example, an island, the length of the measured coastline is dependent on the length of the ruler used. If one were to

\footnotetext{
${ }^{8}$ This fundamental emphasis on non-bifurcated perceiver-environment interaction is also, interestingly, a central idea in 'ecological psychology' (see e.g. Heft, 2001).
} 
measure the coastline with a standard 30 centimetre ruler, the coastline would appear to be considerably longer than when measuring it with a yardstick, since the use of a shorter tool would entail more bumps and curves to measure around. The paradox gets particularly interesting when the hypothetical ruler gets shorter and shorter: as the length of the ruler nears zero, the coastlines theoretical length approaches 'infinity' (or at the very least, 'undefinability') (Mandelbrot, 1967). It follows then that there is no completely definable length for a coastline, since the process of measurement necessarily bears effect on its result.

Here we can note similarities to several process-philosophical themes addressed above: firstly, the coastline is fundamentally incomplete since it escapes precise definition and can (theoretically) diverge to huge lengths and even infinity. Second, the coastline is pragmatically incomplete in that, regardless, it is possible to agree on a certain length by pragmatic methods or political ${ }^{9}$ reasoning. Indeed, evoking the words of polymath Henri Poincaré (1958: 129), the island might be measured 'very nearly' (and enough so for pragmatic application), even if the exact description remains 'necessarily incomplete'. Moreover, the island is processual 'all the way down', since the information we acquire at any scale is dependent on the process of measurement. As Rescher (2000: 81-82) notes, physical nature 'can exhibit a very different aspect when viewed from the vantage point of different levels of sophistication in the technology of the nature-investigator interaction', and is thus cognitively inexhaustible. Thus an analogy to overcome the constructionist-realist debate follows: the coastline's structure undoubtedly is there insofar as it affords measurement and experience (realism), but any acquired information is inherently dependent on the selective act of measurement (constructionism) ${ }^{10}$.

\footnotetext{
${ }^{9}$ It is not far-fetched to draw an analogy here to the political nature of science. Intriguingly, the coastline paradox has in fact resulted in several actual political feuds related to border lengths and territorial ownership.

${ }^{10}$ This should not be, however, read as an offensive towards the scientific enterprise: it is simply the reverse side of science's 'strength as an endlessly versatile intellectual instrument capable of accommodating itself to ever-
} 
Yet even all this is assuming the island and the coastline were an ideal-type static entity, which simply does not apply to real life. Indeed, stepping back on the hypothetical island, we shall notice that the island itself is in dynamic process. Thus not only is the island's coastline not precisely measurable in a static ideal-type situation (due to the processual nature of measurement), it is also embedded in the dynamic process of constant contingencies affecting the measurement. Tides (caused by gravitational effects of the Moon and the Sun as well as the Earth's rotation), erosion (due to water flow and wind), human and other organic impact (including the very act of measurement), climate change (sea level rise) and plate tectonics are all among the indefinite factors constantly shaping and reshaping the island. That is not, of course, even considering the human-scale arbitraries of how to measure around, for example, deltas, estuaries and tidal flats. It follows then that even the island itself is, ontologically speaking, better defined in processual than substantial terms. Islands come and go, emerge and perish ${ }^{11}$, and during any attempt to measure a precise account of a coastline the coastline would have changed. To ontologically describe the island as a substance with fixed properties and borders would be in Whitehead's (1978) terminology a 'fallacy of misplaced concreteness'. The static substance-island can only ever be a pragmatic categorization of the island-in-process. Thus, paraphrasing Heraclitus, 'we do not step twice on the same island', although it is undeniably pragmatic to assert so.

The real insight here is that there is no fundamental reason why the analogy of the coastline paradox shouldn't apply to every form of substance. This 'fuzzying of borders', of course, has often been applied to discussion related to plastic or gradient 'things' such as race, gender and sex (Haraway, 1991), equality (Sen, 1995), ethnicity and identity (Barth, 1969) and even species (Dawkins, 1993). However, analytical process-philosophical applications in these

changing cognitive circumstances' (Rescher, 1984: 4). The perceptive limitation of processual structure when forming conceptual entities is at the heart of all cognitive efforts (see Heft, 2001).

${ }^{11}$ A substance metaphysics would also run into trouble in defining when precisely a substance-island would begin or cease to exist (see Rescher 1996). 
domains remain scarce, and I sincerely believe process philosophy would provide a pragmatic framework for interpreting these (and so many other) issues as well.

In the context of this article, however, applying these insights to the human-nature bifurcation is of the highest importance: there are no fundamentally fixed borders between humans and their environment. Thus, the coastline paradox also provides a metaphorical basis for an ecological reinterpretation of individualism. Although we can pragmatically speak of an individual as a separate entity, it is, like the island, fundamentally embedded in a worldwide web of interrelated processes from which it emerges. Thus even describing an individual in the metaphorical language of 'an island' (e.g. an independent and rational decision maker) should lead to the interpretation that, fundamentally speaking, the individual has no fixed borders and inevitably exists in and under the influence of a world of dynamic socioenvironmental process. As Whitehead (1967: 225) remarks, 'we cannot tell with what molecules the body ends and the external world begins', and hence 'human experience is an act of self-origination including the whole of nature'. This insight, I believe, is fundamental for developing sustainable modes of thought where individual actors simply cannot fundamentally bifurcate themselves from their environment, even if they at times are pragmatically required to do so. Hence, 'no person is an island', or alternatively, people are islands, but 'islands aren't what they appear to be' (Mesle, 2008: 9).

\section{The Process of Tacit Knowing}

I hope to have established by now a comprehensive (albeit brief) reasoning for reframing some of the basic tenets of what might be called 'substantialist' metaphysics in order to draw a process-philosophical bridge between some of its potentially environmentally pathological features. Yet the question of how humans, both the public and experts included, carry these metaphysical convictions requires further illustration. The move is now from ontology- 
oriented analysis to specific epistemology. I shall approach this issue through Michael Polanyi's philosophy of 'personal' (1974) or 'tacit' (2009) knowledge. An afterthought to his accomplished career in physical chemistry, Polanyi sought to develop a philosophical system bridging the knower and the known, the subject and the object as well as facts and values. I argue here that Polanyi presents us with a through and through embodied account of knowledge, carrying with it further implications on how even the most intellectual endeavours are embedded in tacit knowledge arising from socio-ecological process. Polanyi's epistemology can thus be particularly insightful regarding the feedback relations between mental models and human-environment relations. If much of our environmentally oriented decision-making and behaviour arises from embodied, or 'indwelled', tacit knowledge, might we seek to alter environmental behaviour by consciously reframing tacit knowledgeframeworks?

I begin with Polanyi's (2009: 4) simple and heuristic notion that 'we can know more than we can tell'. As Polanyi (1974) himself has acknowledged, for some this statement might seem too obvious to merit high emphasis, whilst for others it might seem to bear almost mystical features. I argue that neither of these claims hold truth, since Polanyi's account of epistemology has profound implications whilst being in no sense logically untenable. The conception that we can know more than we can tell is in its most intuitive (yet impoverished, as shall be explained later) form in acts of physical motion. Polanyi (1974: 49) notes that 'the aim of a skilful performance is achieved by the observance of a set of rules which are not known as such to the person following them'. Indeed, few people familiar with the skilful performance of swimming are consciously aware of the delicate manner in which they keep themselves afloat via regulation of respiration (i.e. maintaining an increased level of buoyancy by refraining from emptying lungs when breathing out and by inflating them more than usual when breathing in). Similarly, the casual cyclist is likely to be completely unaware 
of how balance is maintained through intricate manoeuvres making use of centrifugal forces. These examples are, of course, commonsensical - this is wholly intentional, since much of Polanyi's (1974: 94) work is focussed on drawing a bridge between 'sound common sense' and sophistication. Consequently, the notion of tacit knowing becomes increasingly more intriguing when taking the step from the practical domain to the intellectual.

Although tacit knowledge is often (mistakenly) referred to merely in the context of practical know-how, Polanyi (2009: 7) - who was the first to coin the concept of tacit knowledge - had no intent on separating the practical realm of knowledge from the intellectual. Hence, it cannot be stressed enough that for Polanyi (1969: 133; 1974: 257, 312; 2009) the unformalized tacit coefficient permeates all knowledge, practical and theoretical, and that there are no reasonable grounds to accept a fundamental distinction between the two. The tacit coefficient of knowledge is no 'mere imperfection' but in fact a necessary component of all knowing. Polanyi's (1974: 87, 257) stance, therefore, represents a radical distaste towards the 'Cartesian doctrine of "clear and distinct ideas", and extends the embodied knowledge hypothesis to include the most rational and explicit forms of knowing. ${ }^{12}$

To support the idea that all knowledge is rooted in tacit knowledge, Polanyi (1974: 88) quotes Whitehead (1948: 73) to demonstrate the incomplete ${ }^{13}$ nature of any explicit formalized statement: 'There is not a sentence which adequately states its own meaning. There is always a background of presupposition which defies analysis by reason of its infinitude'. Hence, strictly speaking, nothing we say can be said precisely: every act of explicit statement bears with it a reference to some thing or experience, which at the moment of utterance, remains

\footnotetext{
${ }^{12}$ An analogy here lies to discussion related to the dual mode of cognition, or the idea that humans are characterized by distinguishable type 1 (fast, automatic and unconscious) and type 2 (slow, deliberative and conscious) cognitive processes (see e.g. Hukkinen, 2012; 2016). Polanyi's philosophy supports claims that type 1 ('tacit') and type 2 ('explicit') cognitive processes are deeply intertwined, and that tacit intuitive cognitive processes are fundamental constituents in even the most rational forms of knowing.

${ }^{13}$ It is perhaps noteworthy that much of Polanyi's (1974) philosophy is influenced by Gödel's incompleteness theorems.
} 
tacit and fundamentally incomplete. Whilst we can explicate some of the particulars we are tacitly referring to, this explication only brings forward new tacit presuppositions which would themselves require explanation, ad infinitum. ${ }^{14}$

Ultimately, it follows, to know something is to rely on pragmatic 'common sense' (or a Duhemian bon sens) in the face of fundamental incompleteness. Explicit knowing, then, whilst being a 'superb instrument', ultimately 'requires a background of common sense', or tacit knowledge, for its operational basis (Whitehead, 1948: 74). Whilst tacit knowledge can be possessed or embodied in itself, explicit knowledge must rely on being tacitly understood: all knowledge is 'either tacit or rooted in tacit knowledge' and a 'wholly explicit knowledge is unthinkable' (Polanyi, 1969: 144). It follows, contra the caricaturized 'early Wittgenstein', that we should not be 'quiet of what we cannot speak of' as this would very fundamentally contradict the nature of human knowledge. Formalizing all knowledge to the exclusion of any tacit knowledge is evidently self-defeating (Polanyi, 1969: 133; 1974: 87, 91; 2009: 20).

Formalization can and does, however, immensely expand the powers of the mind, but only when explicit rules sink into the tacit matrix (Polanyi, 1969: 156). Rules or maxims do not determine the practice of the art when alienated, and maxims are only successful guides when embodied and integrated to practice (Polanyi, 1974: 49, 162). Furthermore, when explicit maxims are 'interiorized' (embodied) into the tacit domain they become faster and more intuitive (Polanyi, 1969: 144). This is akin to what Dreyfus and Dreyfus (in Flyvbjerg, 2001: 9-24) and Collins and Evans (2007) call 'expertise': fast, holistic, non-rule based, intuitive and embodied decision-making. It is also what Rochlin (1997) simply calls 'having the bubble'.

\footnotetext{
${ }^{14}$ A clear analogy here could be drawn to the Duhem thesis: no scientific hypothesis can be tested in isolation, since any empirical test is dependent on interconnected auxiliary hypotheses.
} 
Polanyi $(1969 ; 1974 ; 2009)$ argues that the relation between tacit and explicit modes of knowledge is based on the distinction between 'subsidiary' (proximal) and 'focal' (distal) awareness and what Polanyi calls the 'from-to' structure of knowing. In essence, the argument follows: knowledge is formed in the integration of embodied tacit particulars to an explicit whole (Gestalt), to which we attribute meaning. A physiologist who has completely mapped all that takes place in the eyes and brain of a human being does not see what the human being subject to the mapping sees, because the physiologist is merely looking 'at' these happenings and not attending 'from' them 'to' something - this is, of course, not to deny that the physiologist might learn something useful from the mapping process (Polanyi, 1969: 147).

This is particularly what Polanyi $(1974 ; 2009)$ refers to when claiming that we cannot learn an art - or science - by simply learning its maxims, but we learn through experience and its bodily internalization. Only when we subsidiarily interiorize, or embody, an art or scientific theory can we focally interpret things in its light. We attend from tacit subsidiary awareness to focal explicit awareness. Therefore, to rely on a theory for understanding nature is to interiorize it, or to 'dwell' in it (Polanyi, 2009: 17). This is, for Polanyi, the bodily root of all knowledge, and this is also why I consider Polanyi akin to processists. Polanyi (2009: 15) argues that our bodies are the ultimate instruments of all our external knowledge, whether intellectual or practical. Since our body is involved in the process of perceiving external objects, it participates in the process of knowing external things by 'dwelling' in them - it follows that the subject and object are necessarily merged in the act (or process) of knowing (Polanyi 2009: 29). Indwelling applies to all forms of knowledge, both practical and intellectual: similarly to how we dwell in the hammer to drive in a nail we dwell in a scientific theory to make sense of empirical observations (Polanyi 1974: 60). Both are acts of skill and connoisseurship, and both involve a degree of personal commitment, which is hence involved 
in all acts of intelligence (Polanyi 1974: 61). In both acts, consequently, we also rely on embodied tacit knowledge.

Herein, I believe, lies the fundamental insight of Polanyi's philosophy for environmental policy and philosophy. Let us first assume, like Polanyi does, that intellectual and practical knowledge are both bodily functions fundamentally embedded in the tacit domain. It follows, therefore, that any feat of environmental behaviour is not fundamentally rooted in rational explicit knowledge of nature, but rather in our tacit belief frameworks and embodied experience in relation to nature. Consequently, our focal awareness of the environment - that is, the way we experience our environment and attach meaning to it - is embedded in a subsidiary framework which we have tacitly interiorized, embodied, and been 'habituated' to (Dewey, 1958: 14). Polanyi (2009: 17) calls this the 'tacit framework for our moral acts and judgments', the framework 'from' which we attend 'to' things seen in its light. In other words, we have a tendency of projecting our conceptual worldview (which at the moment of observation remains tacit) on how we focally experience, or dwell in, the world ${ }^{15}$.

It follows then that similarly to how the layperson is unaware of the tacit knowledge underlying a simple act as riding a bike, the layperson - or even the expert - is unaware of the primary tacit metaphysical frameworks from which meaning is attached to the socioecological environment. This implies that our environmental action and its precedent moral judgments are tacitly grounded in the (relatively static) metaphysical framework ${ }^{16}$ we have embodied - through culture, tradition, conviviality, authority, and not the least, ecological and

\footnotetext{
${ }^{15}$ Note that this personal coefficient of knowledge is not, in a fundamental sense, subjective (nor a pure 'social construct'), as it is reciprocally shaped by our dynamic interaction with the socio-ecological environment. It would be a dire misrepresentation to portray Polanyi a subjectivist, despite his obvious distaste for impersonal objectivism.

${ }^{16} \mathrm{An}$ analogy can be drawn here to Bijker's (2007: 122) 'technological frame'. Similarly to how technological frames induce stability in 'ways of thinking' and 'fixed patterns of interaction', people dwelling in particular metaphysical tacit frameworks 'will find it difficult to imagine other ways of dealing with the world.'
} 
Forthcoming in Environmental Values @The White Horse Press http://www.whpress.co.uk

evolutionary ${ }^{17}$ processes - and ultimately results in the focal experience by which we prima facie confront the world and attach meaning to it (Polanyi, 1974: 207). We 'believe many things not because they are so,' but because we have been habituated through 'unconscious effects' to do so (Dewey, 1958: 14). We dwell, subsidiarily, in tacit embodied metaphysical convictions which manifest in our focal awareness of the world - we attend from our tacit belief systems to our explicit manner of attaching meaning to the world.

I have already established above that the dominant metaphysical conviction in which we dwell in is one where substance is asymmetrically biased over process. Since knowledge is an activity better described as an embodied 'process of knowing', modifying this 'tacit framework' changes how we dwell in the world (Polanyi, 1969: 134). In other words, tacit belief frameworks manifest themselves in how we act towards nature and the environment. As Dewey (1958: 14) emphasized, 'the ways in which we believe and expect have a tremendous affect upon what we believe and expect'. That such metaphysical convictions, for most, are tacit does not make them any less real, since all knowledge is fundamentally rooted in its tacit predecessor.

Whilst it follows then that this tacit framework will escape any complete explicit formalization, it is reasonable and justifiable to apply pragmatically incomplete measures to attempt to explicate an environmentally unsound tenet of metaphysical thought that much of our civilization dwells in. I have suggested above that we live in a framework of substance metaphysics where the human has separated itself from nature and has justified itself to abuse its environment at the price of both its own and the environment's well-being. As Honig et al. (2015) note, altering environmental behaviour requires a novel understanding of how society and earth systems are connected, yet to achieve this it is simply not enough to attempt to

\footnotetext{
${ }^{17}$ Indeed, to omit biological factors from this list would be folly, although further addressing the question of 'innate cognitive dualism' is out of bounds for this article (see e.g. Slingerland, 2008 for an overview on the topic).
} 
modify human-environment interaction through building on explicit or rational knowledge. A more thorough Gestalt shift in how we attend to the world is required, and I suggest process philosophy can serve as the metaphysical basis for this thorough reinterpretation of humanenvironment interaction. To dwell in a tacit framework of process, due to the five tenets mentioned in Section 2.3., arguably has the potential for being more sustainable and environmentally sound than a substance-biased framework. It is the implementation of this framework, which Gare (1996) has dubbed a 'metaphysics of sustainability', that is left for environmental policy-makers to consider.

\section{Conclusion and Discussion}

So far I have suggested that some of the most environmentally pathological 'bifurcations of nature' arise from substance-biased metaphysics, and thus we might have sufficient reason to look at alternative frameworks for interpreting, and thus dwelling in, reality. As has been noted, a process metaphysical approach might be able to play the active role of such an alternative, much due to its emphasis on the reality of 'change' in nature and the fundamental interconnectedness it ascribes between artificially bifurcated entities such as 'human' and the 'environment' and 'products' and 'processes'. With Polanyi's theory of knowledge I was able to draw the fundamental line of interconnection between mental and physical processes of knowing, thus suggesting that the ways in which we tacitly apply meaning to the world have fundamental effects on how we dwell in our environment. Yet whilst these insights are valuable in themselves, they can also be regarded as pragmatic instruments for facilitating the development of a sustainable culture. Therefore the evident question remains of how to go on about changing the most unsustainable mental models in which human and nature are bifurcated. 
Education, of course, would be the most obvious means. This comes as no surprise since two major figures quoted in this article, Whitehead and Dewey (and to a slightly lesser extent, Polanyi) deeply emphasized the role of education in social progress. Common to these thinkers was a 'process' approach to education; that is, learning should happen through participatory, experiential, transdisciplinary and pragmatic means. Environmental education should not be substance-biased (i.e. merely learning 'about' things), but rather learning through process (i.e. participation and direct experience, thus building on tacit knowledge and expertise). These ideas are in line with claims that strictly rational or explicit learning methods are not alone sufficient to induce sustainable behavioural patterns (see e.g. Kollmuss and Agyeman, 2002). Indeed, other behaviour-affecting parameters suggested in sustainability research, such as values, attitudes, socio-economic processes, awareness, affect, interconnection and involvement could all be interpreted to be at the heart of the processphilosophical inquiry (Kollmuss and Agyeman, 2002; Honig et al., 2015; Richardson et al., 2015).

Yet due to the urgency of the issue at hand (the direct pro-environmental effects of educational reforms, for instance, might take a generation time to fully kick in - far too slow a time scale to tackle immediate ecological crises) it is the responsibility of environmental policy-makers to consider supplements to educational methods and more traditional policy means in order to swiftly move civilization towards sustainable dwelling. Recent discussion in environmental policy (Hukkinen, 2012; 2016), drawing insights from theories of embodied cognition (e.g. Lakoff and Johnson, 1999), has addressed the 'nudging' of mental or cognitive models in order to induce sustainable behaviour patterns. Nudging in this context is to be interpreted as the political means of designing 'cognitively attractive and empirically sound 
mental models that have the capacity to alter people's behaviour toward socio-ecologically sustainable transitions' (Hukkinen, 2012: 2$)^{18}$.

Since I have already addressed that tacit substance-biased mental models might be at the very heart of unsustainable thinking, I propose that policy-makers could find particular interest in process philosophy when designing sustainable cognitive models. Nudging towards processbiased thought could happen, for example, by perpetual and repetitive use of processrelational metaphors (see e.g. Table 1) in textual or visual context in environmental communication, since the 'process' of process thought itself starts with the simple substitution of the fundamental metaphor 'things are static' (substance) with 'things are dynamic' (process). Whilst the concrete development of sustainable process-biased cognitive models ${ }^{19}$ is out of bounds for this article, what should be briefly discussed is what exactly could be expected to result from them.

The intended result is to evoke what is perhaps best described as 'double-loop' thinking. Instead of thinking of things 'as substance' (single-loop), the trick to process-relational thought is to think of 'substance through process' (double-loop) ${ }^{20}$. In Polanyi's (2009) terminology, the process-loop would represent the 'tacit dimension' of thought whereas the substance-loop would represent the business-as-usual 'explicit' dimension. What results is, essentially, 'thinking about thinking' with the caveat that 'thinking' here should largely happen in the tacit dimension for it to be truly habitual and consistent - this is, essentially, 'tacit metacognition' (Swartz and Perkins, 1990).

\footnotetext{
${ }^{18}$ I agree with Hukkinen (2016) in that whilst nudging is not ethically unproblematic, the 'fate of human beings as socially and materially circumscribed organisms is to constantly nudge and be nudged.' Whilst nudging can be criticized on democratic grounds (although I would not regard it being 'eco-authoritarian'; Shahar, 2015), a truly undemocratic society would prevail in a post-ecocide future - it is the wholehearted responsibility of political actors to prevent this future from occurring.

${ }^{19}$ See the 'roller-coaster blend' in Hukkinen, 2012 for what I regard a sustainable process-relational cognitive model.

${ }^{20}$ Recall Rescher's metaphor of substance arising from a 'sea of process'.
} 
If successfully implemented, it is not a long stretch to see this resulting in more sustainable behaviour: complementing substance-bias (e.g. 'I need this thing [substance]...') with process-bias (e.g. ' ...but this thing emerged from [process 1 ] and will result in $\left[\right.$ process $\left._{2}\right]$ ') could result in more sustainable consumption patterns as well as heightened environmental consciousness. To imagine this scenario in, for example, a mundane grocery store setting is even less far-fetched. The single-loop mental scenario 'go to a store [store-substance] and buy familiar food [grocery-substance]' should be replaced by a double-loop mental model of 'think of how to get to the store [process of transport] and how products have become [process of production] and shall become [process of disposal]'. Think of how, for example, the coastline paradox was used above to reframe how we think of an island (from 'island as substance' to 'island as environmentally embedded process'), and how similar mental models could be used to reframe a variety of human-environment relations. Moreover, as was noted in Section 2.3, this tacit substance-bias can also be tackled by other policy means, for example by increasing the frequency of direct feedback in consumption processes (Abrahamse et al., 2007), yet these are certainly only some of many potential process-biased tools for policymakers to consider and experiment with.

Again, however important mental models are for sustainability transitions, all this comes with the significant caveat that developing sustainable mental models should never happen inseparably from broader systemic (social, political or economic) change. The focus should rather be on overcoming this dichotomy between mental models and macro systems altogether by promoting the design of sustainable 'affordances' (Heft, 2001), or behavioural settings which build the necessary pro-environmental capability sets (Sen, 1995) to facilitate the behavioural realisation of sustainable mental models. Whilst further processual investigations and applications are, for now, left to the imagination of the reader, I believe applied process philosophy could prove to be a fruitful framework for environmental policy 
developments, and therefore play a particularly innovative part in the transition towards a sustainable future.

\section{Acknowledgements}

I thank participants at the Environmental Policy Research Seminar 2015-2016 at the University of Helsinki and two anonymous reviewers for their valuable comments on earlier drafts of this article.

\section{References}

Abrahamse, W., Steg, L., Vlek, C. and Rothengatter, T. 2007. 'The effect of tailored information, goal setting, and tailored feedback on household energy use, energy-related behaviors, and behavioral antecedents'. Journal of Environmental Psychology 27: 265-276.

Antal, M. and Hukkinen, J.I. 2010. 'The art of the cognitive war to save the planet'. Ecological Economics 69: 937-943.

Barth, F. (ed.) 1969. Ethnic Groups and Boundaries: The Social Organization of Culture Difference. Bergen: Universitetsforlaget.

Bijker, W. 2007. 'Dikes and dams, thick with politics'. ISIS 98(1): 109-123.

Collins, H. and Evans, R. 2007. Rethinking Expertise. Chicago: University of Chicago Press.

Davis, J.L., Green, J.D. and Reed, A. 2009. 'Interdependence with the environment: Commitment, interconnectedness, and environmental behaviour'. Journal of Environmental Psychology 29: 173-180.

Dawkins, R. 1993. 'Gaps in the mind', in Cavalieri, P. and Singer, P. (eds), The Great Ape Project, pp. 81-87. New York: St. Martin's Griffin.

Dewey, J. 1958 [1925]. Experience and Nature. New York: Dover Publications. 
Forthcoming in Environmental Values @The White Horse Press http://www.whpress.co.uk

Epstein, S. 1994. 'Integration of the cognitive and the psychodynamic unconscious'. American Psychologist 49: 709-724.

Fauconnier, G. and Turner, M. 2002. The Way We Think: Conceptual Blending and the Mind's Hidden Complexities. New York: Basic Books.

Flyvbjerg, B. 2001. Translated by Steven Sampson. Making Social Science Matter: Why Social Inquiry Fails and How It Can Succeed Again. Cambridge: Cambridge University Press.

Gare, A. 1996. Nihilism Inc.: Environmental Destruction and the Metaphysics of Sustainability. Como: Eco-Logical Press.

Gould, S.J. 2000. 'Deconstructing the 'Science Wars' by reconstructing an old mold'. Science 287: $253-261$.

Haraway, D. 1991. Simians, Cyborgs and Women: The Reinvention of Nature. New York: Routledge.

Heft, H. 2001. Ecological Psychology in Context: James Gibson, Roger Barker, and the Legacy of William James's Radical Empiricism. Mahwah: Laurence Erlbaum Associates.

Honig, M., Petersen, S., Herbstein, T., Roux, S., Nel, D. and Shearing, C. 2015. 'A conceptual framework to enable the changes required for a one-planet future'. Environmental Values 24(5): 663-688.

Hård, M. and Jamison, A. 2005. Hubris and Hybrids: A Cultural History of Technology and Science. New York: Routledge.

Hukkinen, J.I. 2012. 'Fit in the body: matching embodied cognition with social-ecological systems'. Ecology and Society 17(4): 30. 
Forthcoming in Environmental Values @The White Horse Press http://www.whpress.co.uk

Hukkinen, J.I. 2014. 'Model of the social-ecological system depends on model of the mind: contrasting information-processing and embodied views of cognition'. Ecological Economics 99: 100-109.

Hukkinen, J.I. 2016. 'Addressing the practical and ethical issues of nudging in environmental policy'. Environmental Values 25(3): 329-351.

Kauffman, S. 1995. At Home in the Universe: The Search for Laws of Self-Organization and Complexity. New York and Oxford: Oxford University Press.

Koestler, A. 1967. The Ghost in the Machine. Hutchinson: London.

Kollmuss, A. and Agyeman, J. 2002. 'Mind the gap: Why do people act environmentally and what are the barriers to pro-environmental behavior?' Environmental Education Research 8(3): 239-260.

Kuhn, T. 2012 [1962]. The Structure of Scientific Revolutions. 50 ${ }^{\text {th }}$ Anniversary Edition. Chicago and London: Chicago University Press.

Lakoff, G. and Johnson, M. 1999. Philosophy in the Flesh: The Embodied Mind and its Challenge to Western Thought. New York: Basic Books.

Latour, B. 1991. We Have Never Been Modern. Translated by Catherine Porter. Cambridge, MA: Harvard University Press.

Leiserowitz, A. 2009. 'Climate change risk perception and policy preferences: The role of affect, imagery and values'. Climatic Change, 77: 45-72.

Mandelbrot, B. 1967. 'How long is the coast of Britain? Statistical self-similarity and fractional dimension'. Science, New Series 156(3775): 636-638. 
Forthcoming in Environmental Values @The White Horse Press http://www.whpress.co.uk

Mesle, C.R. 2008. Process-Relational Philosophy: An Introduction to Alfred North Whitehead. West Conshohocken: Templeton Foundation Press.

Ostrom, E. 2005. Understanding Institutional Diversity. Princeton: Princeton University Press.

Poincaré, H. 1958 [1905]. The Value of Science: Essential Writings of Henri Poincaré. Translated by George Halsted. New York: Dover Publications.

Polanyi, M. 1969. Knowing and Being: Essays by Michael Polanyi. Edited by Marjorie Grene. Chicago: The University of Chicago Press.

Polanyi, M. 1974 [1958]. Personal Knowledge: Towards a Post-Critical Philosophy. London: The University of Chicago Press.

Polanyi, M. 2009 [1966]. The Tacit Dimension. Chicago and London: The University of Chicago Press.

Rescher, N. 1984. The Limits of Science. London: The University of California Press.

Rescher, N. 1996. Process Metaphysics: An Introduction to Process Philosophy. Albany: State University of New York Press.

Rescher, N. 2000. Process Philosophy: A Survey of Basic Issues. Pittsburgh: University of Pittsburgh Press.

Richardson, M., Hallam, J. and Lumber, R. 2015. 'One thousand good things in nature: Aspects of nearby nature associated with improved connection to nature'. Environmental Values 24(5): 603-619.

Rochlin, G.I. 1997. Trapped in the Net: The Unanticipated Consequences of Computerization. Princeton: Princeton University Press. 
Forthcoming in Environmental Values (CThe White Horse Press http://www.whpress.co.uk

Sen, A. 1995. Inequality Reexamined. Cambridge, MA: Harvard University Press.

Shahar, D.C. 2015. 'Rejecting eco-authoritarianism, again'. Environmental Values 24(3): 345-366.

Slingerland, E. 2008. What Science Offers the Humanities. New York: Cambridge University Press.

Stengers, I. 2011. Thinking With Whitehead: A Free and Wild Creation of Concepts.

Translated by Michael Chase. Cambridge, MA and London: Harvard University Press.

Swartz, R. and Perkins, D.N. 1990. Teaching Thinking: Issues and Approaches. Pacific Grove: Critical Thinking Press \& Software.

Whitehead, A.N. 1948. Essays in Science and Philosophy. London: Rider and Company.

Whitehead, A.N. 1967 [1933]. Adventures of Ideas. New York: The Free Press.

Whitehead, A.N. 1978 [1928]. Process and Reality (Corrected Edition). Edited by David Ray Griffin and Donald W. Sherburne. New York: The Free Press. 


\section{Tables}

Table 1: Ontological or Epistemological Primacy (based on Rescher 1996; 2000)

\begin{tabular}{|c|c|}
\hline Substance Philosophy & Process Philosophy \\
\hline staticity & dynamicity \\
\hline discrete individuality & interactive and reciprocal relatedness \\
\hline separateness & wholeness (totality) \\
\hline humans, society $\quad$ nature, environment & socio-environmental process \\
\hline classificatory stability, completeness & classificatory fluidity, incompleteness \\
\hline passivity (things acted upon) & activity (agency) \\
\hline product (thing) & process \\
\hline persistence & change, novelty \\
\hline being & becoming \\
\hline digital discreteness & analogical continuity \\
\hline
\end{tabular}

\section{Table 2: Processual Reframing of Environmentally Pathological Substance-Bias}

\begin{tabular}{|l|}
\hline 1. Human and environment are unified under a comprehensive processual framework. \\
\hline 2. Things are what they do and how they become: process has priority over product. \\
\hline 3. The ontological status of change (e.g. climate change) is strengthened. \\
\hline 4. Potential alternative for the realist-constructionist debate and the science wars. \\
\hline 5. Individual actors are merged with their systemic counterparts and vice versa. \\
\hline
\end{tabular}

